\begin{tabular}{|c|c|c|c|c|}
\hline \multirow[b]{2}{*}{ No. } & \multirow{2}{*}{$\begin{array}{l}\text { Sample of } \\
\text { whiskey. }\end{array}$} & \multicolumn{2}{|c|}{ Allen-Marquardt method } & \multirow{2}{*}{$\begin{array}{c}\text { Roese } \\
\text { method. } \\
\text { By volume. }\end{array}$} \\
\hline & & By weight. & By volume. & \\
\hline I & Tennessee. ............ & II 3.0 & I 38.6 & 276.2 \\
\hline 2 & $\ldots \ldots \ldots \ldots \ldots \ldots$ & 108.3 & 132.9 & 265.2 \\
\hline .3 & Bourbon $\ldots \ldots \ldots \ldots \ldots \ldots$ & +8.5 & $59 \cdot 5$ & $165 \cdot 7$ \\
\hline+ & $\ldots \ldots \ldots \ldots \ldots$ & +6.1 & 56.6 & III.6 \\
\hline 5 & $\ldots \ldots \ldots \ldots \ldots$ & (1) 1,5 & $1.2+5$ & 2.37 .6 \\
\hline 6 & $\ldots \ldots \ldots$ & $47 \cdot 5$ & 159.6 & $\therefore 21,0$ \\
\hline$\ddot{i}$ & $R_{y} y \ldots \ldots \ldots \ldots \ldots$ & $7+\cdots$ & 40.3 & $\therefore 26.5$ \\
\hline Y & $\ldots \ldots$ & $1,2,1)$ & $\%(0.0)$ & $182 . .2$ \\
\hline 1 & $\cdots \quad \ldots \quad \ldots$ & $1+4.11$ & 182.8 & 34.8 \\
\hline (1) & $\ldots \ldots \ldots \ldots$ & $1,31,0$ & $1(x) .7$ & $\therefore 05 \ldots$ \\
\hline iI & 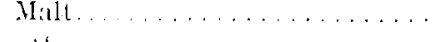 & 105,1 & 128.9 & 296.3 \\
\hline 12 & “ $\ldots \ldots \ldots \ldots \ldots \ldots \ldots$ & I(1) +.5 & 128.2 & $254 \cdot 1$ \\
\hline
\end{tabular}

Fllsel oil: Patts per 100,000 in 100 proof alcohol,

This investigation leads me to the conclusion that the Allen-Marquardt method, is superior to the Roese method for the following reasons: First, it is more rapid; second, it possesses fewer sources of error, and third, it gives more nearly the amyl alcohol content.

The analytical results by the Roese method recorded in this paper were obtained by my assistant, Mr. Addison Cooper, Jr., to whom I desire to express iny appreciation.

FURMAN Hali, VANIERBILT UNIVERSITY, NASHVILLE, TEN.

\title{
THE ESTIMATION OF ALCOHOL IN FERMENTED LIQUIDS.
}

BY Wh. ANTONI.

Received Jane I2, I90s.

Alcohol in fermented liquids is usually determined as follows: A certain amount of the liquid is measured in a flask, distilled, the distillate collected in the same flask and restored to the original volume. Then the specific gravity of the thtid is determined by means of an accurate pycnometer, and the amount of alcohol found by calculation. This method requires a number of adjustings at a constant temperature, which are tedious and productive of errors.

As the price of fortified wines depends largely on their alcoholic strength, determined to tenths of one per cent., and as often large quantities change hands at a time, it is of importance to have a way of determining alcohol, which combines speed with accuracy.

The following method has been found to comply with these requirements: The liquid is measured in a pycnometer of the Sprengel type, the distillate collected in it without the help of a second measuring flask, and weighed. The pycnometer (Fig. I) has a capacity of about $50 \mathrm{cc}$. The body is cylindrical with a dianeter of $3 \mathrm{~cm}$. and a height of $7 \mathrm{~cm}$. The tubes $a$ and $b$ are $8 \mathrm{~cm}$. long and have a bore of about $\mathrm{r} .5$ and 0.75 
mm., respectively. The wider tube has a circular mark, and both are fitted with caps. The pycnometer is filled with the liquid through a funnel, connected with the wider tube by means of rubber tubing. After standing in a bath of constant temperature for a sufficient length of time it is adjusted by removing liquid from the narrow tube with filter paper, using its edge for the finer adjustment. Now the liquid is poured into a distilling flask, $f$, with the help of a rinsing arrangement (Fig. 2). The flask is held at an angle of about $45^{\circ}$ and the wide tube, $b$, of the pycnometer placed in its mouth.

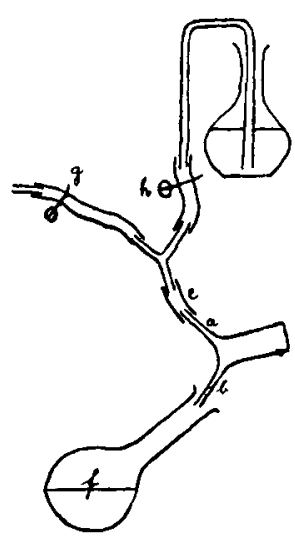

Fig. 2.

The narrow tube, $a$, is

then connected with

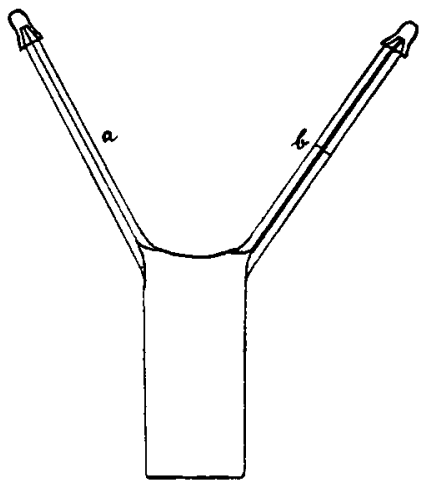

Fig. I. the rinser through tube $c$, and the liquid blown out of the pycnometer through tube $b$, while pinchcock $g$ is kept open. After this, pinchcock $h$ is opened and water admitted through tube $a$ and blown out again, thus rinsing the pycnometer out. The flask is now connected with the upper end of a condenser, the pycnometer with the lower (Fig. 3), and the alcohol distilled over. At the end of this operation the pycnometer is disconnected and almost filled with distilled water from a pipette through the wide tube. The contents are thoroughly mixed by shaking (the tubes being kept closed with the fingers), and the pycnometer is entirely filled through the narrow tube. After again reaching the temperature of the bath it is adjusted as before and weighed.

Aside from the errors in adjusting, etc., an inaccuracy of 0 . I per cent. and more may be introduced by the changes in the specific gravity of the air. The displacement of the pycnometer is about $50 \mathrm{cc}$. more than that of the weights. Taking $770 \mathrm{~mm}$. at $10^{\circ}$ and $740 \mathrm{~mm}$. at $30^{\circ}$ as the extremes in temperature and barometric pressure, one $\mathrm{cc}$. of air would weigh about $\mathrm{I} .26$ and I. $13 \mathrm{gm}$., respectively. For $50 \mathrm{cc}$. of air this

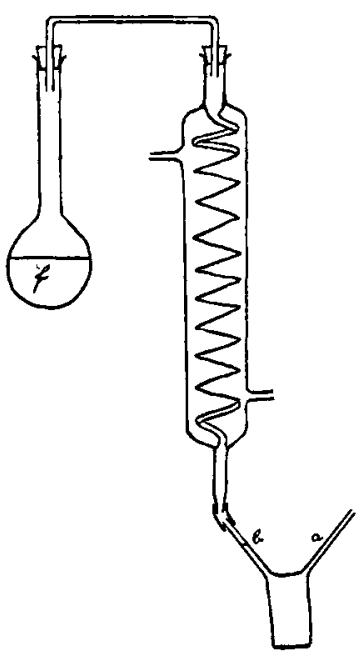

Fig. 3. means a difference of $6.5 \mathrm{mg}$., that is, an error of 0.13 per cent. for 50 grams of liquid. This would necessitate a correction of every deter- 
mination, causing unwelcome work, when a number of analyses have to be made. This can be avoided by using a tare of approximately the same weight and volume as the full pycnometer. Only a few small weights are then used for each weighing and require no correction. The following experiments with three prcnometers were carried out in this way. The liquid used was a sherry wine of about 20 per cent. (vol.) of alcohol:

The capacity of the pycnometers was:

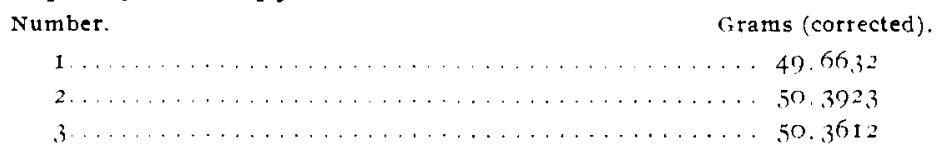

The adjusting was done in a water bath of $15.6^{\circ}$, which temperature was kept fairly constant by addition of ice and occasional stirring. The tare was suspended over the right hand pan of the balance, and the results were as follows:

\begin{tabular}{|c|c|c|c|}
\hline & \multicolumn{3}{|c|}{ Pycnometer number } \\
\hline & 1. & 2. & 3. \\
\hline Pycnometer + dist. water $=$ tare $+\ldots \ldots$ & $2.42,30$ & $5.26,37$ & 5.243 .5 \\
\hline Pycnometer + distillate $=$ tare $+\ldots \ldots \ldots$ & 1,2490 & 4.07 .37 & $4.0,522$ \\
\hline Difference. . & $1.1,46$ & 1.1900 & 1. 1913 \\
\hline
\end{tabular}

By subtracting these differences from the capacities (corr.) of the pycnometers we get the weights (corr.) of the distillates:

Number.

2

3
Grams.

4.4 .4886

49.2023

49.1609

These, divided by the capacities, give the specific gravities of the distillates and the percentage of alcohol in the distillate as well as the original liquid:

\begin{tabular}{|c|c|c|}
\hline Number. & specific gravity. & Volume per cent. \\
\hline $\mathbf{I}$. & 0.976 .31 & 19.77 \\
\hline $2 \ldots$ & .0 .97638 & 19.70 \\
\hline $3 \ldots \ldots$ & .0 .97634 & 19.74 \\
\hline
\end{tabular}

A second series gave:

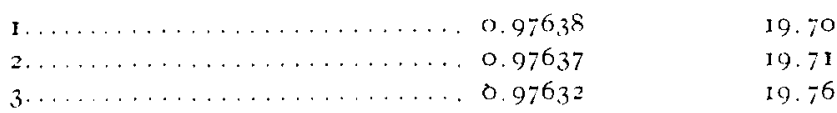

These experiments were carried out in the laboratory of the winery of Lachman \& Jacobi, at Petaluma, Cal., and will be continued.

The pycnometers were made by R. Burger \& Co., Chausseestr. 2 E., Berlin, Germany.

Petaluma, Cal. 